\title{
GAGARINITA-(Y) COM POLIMORFO DE FLUOCERITA: PROVÁVEL CASO DE FORMAÇÃO DE UM NOVO MINERAL POR EXSOLUÇÃO DE ETRL A PARTIR DE FLUORETO DE ETRLP (MINA PITINGA-AM)
}

\author{
AMANDA CRISTINA PIRES ${ }^{1}$, ARTUR CEZAR BASTOS NETO ${ }^{1}$, VITOR PAULO PEREIRA ${ }^{1}$, \\ NILSON FRANCISQUINI BOTELHO², ORLANDO RENATO RIGON MINUZZI'
}

\begin{abstract}
In Pitinga mine, the primary ore ( $\mathrm{Sn}, \mathrm{Nb}$, Ta and cryolite) is associated to albite granite facies of Madeira granite. The cryolite ore occurs disseminated and in a massive deposit. The (Y)-gagarinite occurs in the low levels of the cryolite massive deposit. The crystals show anhedral, up to $7 \mathrm{~mm}$, which are either interstitial or included in the criolite. Its composition $\left(\mathrm{Na}_{0,24} \mathrm{C}\right.$ $\mathrm{a}_{0,58} \mathrm{Y}_{1,01} \mathrm{ETR}_{0,39} \mathrm{~F}_{5,81}$ ) is characterized by enrichment in HREE compared with LREE. In gagarinite occur LREE fluoride crystals distributed with several patterns, varying from irregular and without orientation until to strings and stringlets forms, interpretated as result of exsolution process. The composition of the exsolved phase $\left(\mathrm{Ce}_{0,53-0,06} \mathrm{La}_{0,09-0,26} \mathrm{Nd}_{0,08-0,26} \mathrm{Sm}_{0,01-0,04} \mathrm{Eu}_{0,01} \mathrm{Y}_{0-0.03} \mathrm{~F}_{3,3-4,414}\right)$ is similar to that of fluocerite, which peaks, however, don't appear in the XRD. The REE pattern of this phase shows fractionation with continuous HREE depletion. The initial gagarinite $\left(\mathrm{Na}_{0,23} \mathrm{Ca}_{0,53} \mathrm{ETRa}_{0.99} \mathrm{Y}_{0,48} \mathrm{~F}_{7.69}\right)$, established according to modal proportions and densities of host and exsolved phases, has LREE content much higher than that found in natural gagarinites. The mineral system before exsolution may be described as a solid solution $\left(\square+\square \square+2 \mathrm{ETR}^{3+} \Leftrightarrow \mathrm{Na}^{+}+\mathrm{Ca}^{2+}+\mathrm{Y}^{3+}\right)$, forming a meta-stable gagarinite with LREE content exceptionally high, whose presence was compensated by vacancies in the VI sites. Decreasing in temperature caused LREE exsolution. The residual fase kept $\mathrm{Y}, \mathrm{HREE}$ and $\mathrm{Na}$ contents, establishing a structure with less vacancies and better charge balance. The exsolved phase, with a cation/fluorine ratio $=1 / 3$, is unlike to have a structure similar to that of the gagarinite. Further investigation will be necessary to define its nature and its relationship with fluocerite

Keywords: gagarinite,exsolution, Pitinga

Resumo Na mina Pitinga, o minério primário ( $\mathrm{Sn}, \mathrm{Nb}$, Ta e criolita) está associado à fácies albita granito do granito Madeira. $O$ minério de criolita ocorre disseminado e na forma de um depósito maciço. A gagarinita-(Y) encontra-se associada a criolita na porção inferior desse depósito. Os cristais são anédricos, com até $7 \mathrm{~mm}$, intersticiais ou inclusos na criolita. A composição $\left(\mathrm{Na}_{0}\right.$ ${ }_{24} \mathrm{Ca}_{0,58} \mathrm{Y}_{1,01} \mathrm{ETR}_{0,30} \mathrm{~F}_{5,81}$ ) é caracterizada por enriquecimento em ETRP em relação aos ETRL. Na gagarinita-(Y) ocorrem cristais de fluoreto de ETRL distribuídos com padrões desde irregulares e sem orientação até formas de strings e stringlets, interpretados como resultantes de processo de exsolução. A composição da fase exsolvida $\left(\mathrm{Ce}_{0,53-0,60} \mathrm{La}_{0,09-0,26} \mathrm{Nd}_{0,08-0,26} \mathrm{Sm}_{0,01-0,04} \mathrm{Eu}_{0,01} \mathrm{Y}_{0-0,03} \mathrm{~F}_{3,3}\right.$ 4,14 ) é similar à da fluocerita que, entretanto, não é identificada nos difratogramas de raios X. O padrão de ETR desta fase mostra um fracionamento, com empobrecimento contínuo de ETRP. A gagarinita inicial $\left(\mathrm{Na}_{0,23} \mathrm{Ca}_{0,53} \mathrm{ETRa}_{0,99} \mathrm{Y}_{0,48} \mathrm{~F}_{7,69}\right)$, reconstituída a partir da proporção modal e densidades das fases hospedeira e exsolvida, tem conteúdo em ETRL muito acima do encontrado em gagarinitas naturais. Antes da exsolução, teria existido uma única fase mineral homogênea que correspondia a uma solução sólida $\left(\square+2 \mathrm{ETR}^{3+} \Longleftrightarrow \mathrm{Na}^{+}+\mathrm{Ca}^{2+}+\mathrm{Y}^{3+}\right)$, consistindo em gagarinita meta-estável excepcionalmente rica em ETRL cuja presença é compensada por vacâncias no sítio VI. Com o resfriamento, exsolveram-se apenas os ETR com raios iônicos maiores do que o do Sm. A fase residual manteve os conteúdos de Y, ETRP e Na da solução sólida, estabilizando-se numa estrutura com menos vacâncias e melhor balanço de cargas. A fase exsolvida, com uma razão cátions/flúor $=1 / 3$, dificilmente poderia ter estrutura semelhante à da gagarinita. Serão necessários estudos subseqüentes para definição de sua natureza e relação com a fluocerita.
\end{abstract}

Palavras-chave: gagarinita, fluocerita, exsolução, Pitinga

INTRODUÇÃo A mina de Pitinga, explorada pela Mineração Taboca S.A., é a maior produtora de Sn do Brasil. O minério aluvionar, descoberto em 1978 (in Veiga Jr. et al 1979), encontra-se em vias de exaustão. Em 1983, foi descoberto o minério primário, associado à fácies albita granito do granito Madeira. Trata-se de um depósito de $\mathrm{Sn}$ de classe mundial, que contém importantes reservas de $\mathrm{Nb}$, Ta e criolita explorados como coprodutos e de Zr, ETR, Y, Li e U que deverão ser aproveitados como sub-produtos. A mineralização de criolita de Pitinga é o segundo caso mundial de depósito passível de exploração econômica. A mina de criolita de Ivigtut (Groenlândia) foi desativada nos anos 80 após quase 1 século em produção. Como Ivigtut, o depósito de Pitinga contém uma paragênese muito original, com minerais raros, minerais novos recentemente descobertos, e alguns minerais mais comuns, mas que aí ocorrem com distribuição, composição e ordem de cristalização inusitadas.

$\mathrm{Na}$ área de Pitinga, as rochas mais antigas compreendem gnaisses e granitóides do Complexo Guianense (Issler et al. 1974).
A unidade Suíte Água Branca composta por granitóides calco-alcalinos metaluminosos a peraluminosos é posterior (Almeida $e t$ al. 1997). Sucedida a estas, ocorrem rochas vulcânicas efusivas, piroclásticas e hipabissais, intermediárias e ácidas do Grupo Iricoumé (Costi et al. 2000), que é cortado por corpos graníticos da Suíte Intrusiva Mapuera, como granitos Madeira e Agua Boa, portadores do minério primário em Pitinga. Seguem na coluna estratigráfica, a Formação Urupí (rochas sedimentares flúvio-eólicas e piroclásticas), a Formação Quarenta Ilhas (gabros, diabásios e diferenciados ácidos toléticos) e a Formação Seringa (derrames básicos alcalino-potássicos, diabásios e raros andesitos).

Nos últimos dois anos, foi desenvolvido o projeto FINEPCTMINERAL "Caracterização de depósitos minerais em distritos mineiros da Amazônia", coordenado pelo Departamento Nacional da Produção Mineral e pela Agência para o Desenvolvimento Tecnológico da Indústria Mineral do Brasil, no qual o estudo da mineralização de criolita de Pitinga coube à Universidade Federal do Rio Grande do Sul em associação com a 
empresa mineradora. Durante o estudo, procurou-se investigar, também, a mineralização de Y e ETR e fornecer subsídios para sua exploração como subproduto.

As investigações revelaram a presença de gagarinita-(Y) nos bolsões de criolita da base do Deposito Criolítico Maciço. Trata-se de um mineral que, além de raro, apresenta, no caso de Pitinga, texturas de exsolução que, ao nosso conhecimento, nunca foram descritas em fluoretos. $O$ presente trabalho enfoca aspectos mineralógicos desta ocorrência de gagarinita-(Y). Conclui-se que sua formação ocorreu a partir de uma gagarinita(Y) inicial metaestável devido a um conteúdo excepcionalmente alto de ETR, mais particularmente ETRL. A desestabilização de sua estrutura promoveu a exsolução praticamente total dos ETRL, formando uma gagarinita-(Y) que, mesmo assim, se encontra entre as gagarinitas mais ricas em ETR, e uma fase exsolvida rica em ETRL, de composição similar à fluocerita, com uma estrutura que ainda não pode ser definida, mas que se trata, possivelmente, de um novo mineral.

TRABALHOS ANTERIORES O granito Madeira (Fig. 1) é dividido em quatro fácies (Costi 2000): (1) a fácies anfibóliobiotita sienogranito, a mais precoce, é metaluminosa, equigranular a porfirítica, constituída por feldspato pertítico, quartzo, plagioclásio, biotita e hornblenda, e os acessórios zircão, fluorita e opacos; (2) a fácies biotita-feldspato-alcalino granito é metaluminosa a peraluminosa, equigranular, localmente porfirítica, composta por feldspato pertítico e quartzo, com plagioclásio em proporções reduzidas a nulas, a única fase varietal é a biotita e os minerais acessórios são fluorita, zircão, opacos e topázio; (3) a fácies feldspato alcalino granito hipersolvus é composta por feldspato potássico, por vezes pertítico, quartzo e albita tardia, sendo a biotita o mineral varietal e os acessórios fluorita, zircão e opacos; (4) a fácies tardia, o albita granito, foi subdividida por Horbe et al. (1985) e Teixeira et al. (1992) nas subfácies albita granito de núcleo (AGN) e albita granito de borda (AGB).

Estas fácies tem mergulhos de $10^{\circ}$ a $20^{\circ}$ para os quatro quadrantes, configurando uma forma geral abaulada, com a concavidade voltada para baixo.

O AGN tem coloração acinzentada, é constituído essencialmente por quartzo, albita e feldspato potássico, os minerais varietais são criolita, duas variedades de micas escuras (tetraferrífera e polilitionita) e riebeckita e os acessórios são zircão, cassiterita, variedades de pirocloro, columbita e torita (Costi 2000). Texturalmente, é porfirítico ou seriado com granulação fina a média (Minuzzi et al. 2005). O AGB tem coloração marrom escura a avermelhada, é composto por quartzo, albita, feldspato potássico como minerais essenciais, contém fluorita, cassiterita, hematita, torita, columbita e zircão como minerais acessórios. Texturalmente, é similar ao AGN de núcleo, diferenciando-se deste pela oxidação e forte alteração hidrotermal (Costi 2000). O albita granito foi interpretado por Horbe et al. (1985) como apogranito. Costi (2000) defende uma origem magmática.

O minério de Sn ocorre no AGN e no AGB. Ainda no AGN, ocorrem um depósito criolítico maciço (DCM), minério disseminado de criolita e minério disseminado de $\mathrm{Nb} / \mathrm{Ta}$ (pirocloro). No AGB, a mineralização de $\mathrm{F}$ é representada por fluorita e o minério de $\mathrm{Nb} / \mathrm{Ta}$ é a columbita (Costi 2000). O DCM, que ocorre na porção central do $\mathrm{AGN}$, é acumulado em duas zonas criolíticas A. Cada zona é constituída por intercalações de bolsões pegmatíticos e de rocha encaixante.

Interdigitados com os bolsões criolíticos, no seu topo e nas laterais do DCM ocorrem porções pegmatóides (Costi 2000) constituídas por lentes de feldspato alcalino mesopertítico, quartzo leitoso e hialino e, em menor proporção, por concentrações maciças de micas escuras, bem como criolita e galena, sendo estas últimas de ocorrência mais localizada. O contato com os bolsões criolíticos pode ser brusco ou marcado por uma auréola constituída por micas claras e zircão ou por uma maior concentração de micas escuras, criolita e zircão disseminados.

Gagarinita e Fluocerita A gagarinita-(Y) é um mineral raro. Seu nome homenageia o astronauta russo Yuri Gagarin. A primeira ocorrência é descrita em granitos albitizados, associada a veios de quartzo-microclina, nos Maciços Verkhnee Espe e Kent (Kazakistão), por Stepanov e Severov (1961 apud Hughes e Drexler 1994). Porém, esse mineral também foi identificado no Complexo Strange Lake, em Shar Tolgoi (Mongólia), Gjerdingselva (Noruega), no depósito de $\mathrm{Nb}$-Ta Katungino (Rússia) e Washington Pass (USA). A bibliografia sobre a gagarinita-(Y), além de pouco numerosa, encontra-se principalmente em russo. Apenas quatro outras ocorrências constam no Mineralogy Database, onde o arranjo estrutural disponível mostra que, na gagarinita, os cátions estão distribuídos em dois sítios cristalográficos, um com ${ }^{\mathrm{VI}} \mathrm{Na}$ e outro com ${ }^{\mathrm{IX}}(\mathrm{Ca}, \mathrm{Y}$ e ETR $)$, podendo haver também a presença de ${ }^{\mathrm{IX}} \mathrm{Na}$. O mineral pertence ao sistema hexagonal, grupo espacial $\mathrm{P}_{3} / \mathrm{m}$ (Mandarino \& Black 2004). Em um caso (Voronkov et al. 1962, apud Mincrist.), é descrita como pertencente ao sistema trigonal, grupo espacial P3(-).

A fórmula da gagarinita segundo Mincrist é $\mathrm{Na}(\mathrm{Y}, \mathrm{Ca})_{2}(\mathrm{~F}$, $\mathrm{Cl})_{6}$ ou $\mathrm{NaCaY}(\mathrm{F}, \mathrm{Cl})$. Segundo Hughes e Drexler (1994), a fórmula geral seria $\mathrm{Na}_{x}\left(\mathrm{Ca}_{x} \mathrm{ETR}_{2-\mathrm{x}}\right) \mathrm{F}_{6}$. Nas descrições disponíveis, constata-se que os conteúdos de $\mathrm{Na}$ e $\mathrm{Ca}$ podem ser muito variados, mas estes elementos estão sempre presentes. Em todos os casos, o conteúdo de $Y$, é sempre superior ao de ETR, inclusive na fórmula sugerida por Hughes e Drexler (1994), pois, nesta, o Y é considerado como ETR. Em um caso (Voronkov et al. 1962, apud Mincrist) não foi verificada a ocorrência de ETR.

Macroscopicamente, é transparente e pode ocorrer nas cores amarela, branca, creme, marrom claro ou rosa. O brilho é vítreo, o hábito é maciço. Apresenta fraturas irregulares e clivagem incipiente $\{0001\}$. Tem densidade 4,21 e dureza 4,5 (Clark 1993 apud Minerology Database).

A primeira amostra de gagarinita de Pitinga foi coletada por O. Minuzzi. Resultados de estudos preliminares nesta amostra constam em Bastos Neto et al. (2004) que relatam a existência de inclusões de fluocerita na gagarinita.

A fluocerita é descrita pela fórmula $(\mathrm{Ce}, \mathrm{La}) \mathrm{F}_{3}$ (Styles e Young 1983), pertence ao sistema hexagonal, grupo espacial $\mathrm{P}_{3} / \mathrm{mcm}$ (Mandarino \& Black 2004). Os cátions, em geral com valência +3 estão em um único sítio. $O$ mineral é descrito com hábito prismático ou tabular, e também maciço ou granular; tem brilho vítreo a resinoso e cor amarela, que com a alteração, torna-se castanha avermelhada (Palache et al. 1951 apud Teixeira 2002), a diafaneidade é transparente a translúcida (Clark 1984 apud Teixeira). A fluocerita tem dureza entre 4 e 5, densidade 6,14, fratura conchoidal, clivagem $\{0001\}$ distinta $\mathrm{e}$ $\{112(-) 0\}$ indistinta (Teixeira 2002), é uniaxial(-) e apresenta geminação polissintética, que faz ângulo de $45^{\circ}$ com a clivagem $\{0001\}$ (Heinrich e Gross 1960 apud Teixeira 2002; Clark 1984 apud Teixeira 2002).

METODOLOGIA A seleção de intervalos de sondagem para descrição detalhada e amostragem considerou os intervalos com teores de Y maiores que 0,1\% (não se dispõe de análises de ETR em testemunhos). Adicionalmente, todos os intervalos onde a gagarinita foi tentativamente identificada macroscopicamente foram amostrados. As amostras coletadas foram analisadas em lupa binocular e 10 delas foram selecionadas para confecção de lâminas petrográficas.

As lâminas com gagarinita foram descritas ao microscópio petrográfico, tendo sido determinadas sua paragênese e associação, assim como a ordem de cristalização dos minerais. Tam- 

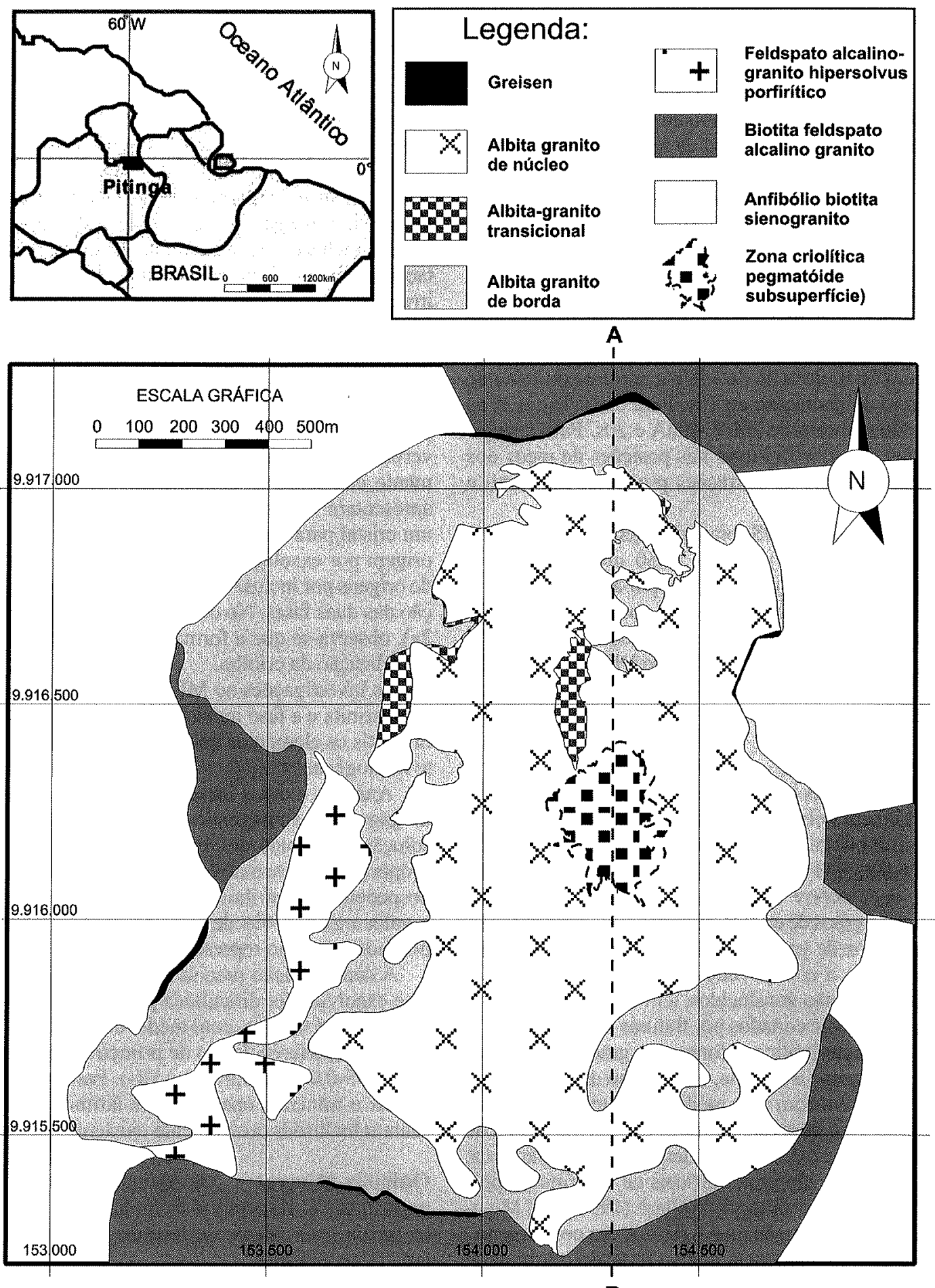

B

A

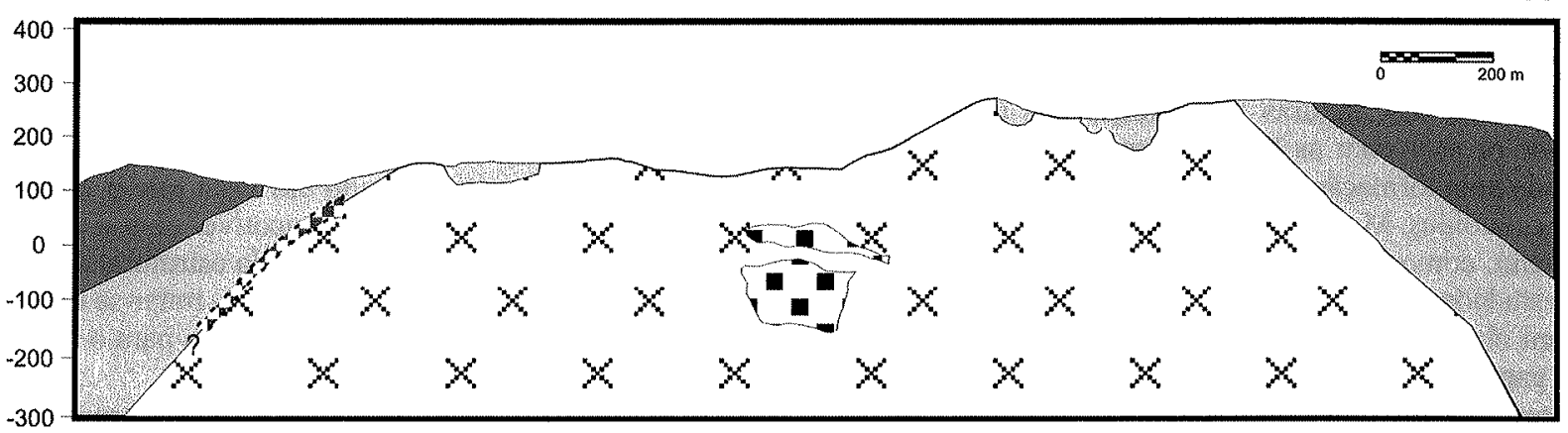

Figura 1: Mapa e perfil geológicos do granito Madeira (Minuzzi 2005). 
bém foram determinadas as proporções modais da fase inclusa relativamente à gagarinita em diferentes grãos por tratamento de imagens, utilizando o Programa Scion Image Beta 4.20.

As análises por difração de raios $\mathrm{x}$ de duas amostras foram realizadas em um equipamento marca Siemens, modelo D-5000, no intervalo entre 2 a $82^{\circ} 2 \theta$, com passo de $0,02^{\circ} 2 \theta$ no tempo de $1 \mathrm{~s}$, utilizando radiação $\mathrm{Co}-\mathrm{K} \alpha$ e filtro de níquel. Os parâmetros cristalográficos da gagarinita foram refinados com o programa "Least-squares Refinement of Crystallographic Lattice Parameters" (LCLSQ 8.5, Burnham 1993), utilizando 10 reflexões em uma amostra (YT) e 12 na outra (FC8). Os erros nas constantes a e c das amostras foram, respectivamente, 0,00264 e 0,00288, para amostra YT e 0,00570 e 0,00582 para amostra FC8

Para a quantificação de $\mathrm{Ca}, \mathrm{Na}, \mathrm{Al}, \mathrm{Si}$ e $\mathrm{F}$ na gagarinita e na fase inclusa foi utilizada a microssonda eletrônica Cameca, SX50 , com voltagem de aceleração de $15 \mathrm{kV}$ e corrente do feixe de $25 \mathrm{nA}$, com tempo de contagem de $10 \mathrm{~s}$. Para os ETR e o Y, as condições de análise foram de $20 \mathrm{kV}, 40 \mathrm{nA}$ e $20 \mathrm{~s}$. Para corrigir os erros causados por interferências nas posições de picos dos ETR foram usados fatores de correções propostos por Åmli e Griffin (1975).

Análises qualitativas de EDS foram obtidas por microscopia eletrônica de varredura (MEV) Phillips XL30, utilizando a energia de $20 \mathrm{kv}$ e tempo de contagem de 200 s por análise.

As análises por DRX foram realizadas nos Laboratórios do Centro de Pesquisas em Geoquímica da UFRGS, as por MEV no Laboratório de Microscopia Eletrônica da UFSC e as por ME no Laboratório do Instituto de Geociências da Universidade de Brasília (UnB).

\section{RESULTADOS}

Ocorrência e observações petrográficas A gagarinita ocorre no granito Madeira em bolsões criolíticos desde a porção mediana até base da Zona Criolítica B. O mineral foi identificado em três furos de sondagem (FC-08, FC-13 e FC-17), entre as cotas $-94 \mathrm{~m}$ e $-140 \mathrm{~m}$, onde ocorre como cristais isolados, localizados intersticialmente aos grãos de criolita ou como inclusões. Macroscopicamente, os grãos de gagarinita destacam-se pela cor (rosa acastanhada) em meio a criolita (branca, amarela ou caramelo) dos bolsões. Os cristais são translúcidos, têm brilho vítreo a resinoso e são freqüentemente cortados por fraturas irregulares.

Ao microscópio petrográfico, a forma dos grãos de gagarinita é anédrica, a clivagem é indistinta. O tamanho dos cristais vam ria de $0,5 \mathrm{~mm}$ até $6,8 \mathrm{~mm}$, com uma média de $3 \mathrm{~mm}$. Eles têm um fraco pleocroísmo, com cores que variam de incolor a tons de rosa, verde ou amarelo, e o relevo é moderado. À luz polarizada, as cores de interferência são muito dificeis de determinar, pois variam num mesmo grão, mas segundo Clark (1993 apud Minerology Database), a birrefringência é 0,020 . À luz convergente, a figura de interferência evidencia que se trata de um mineral uniaxial $(+)$. Como inclusões minerais, ocorrem a fase exsolvida (ver adiante) e opacos (hematita e possivelmente outros). Inclusões fluidas podem ser abundantes e são facilmente observadas mesmo nas lâminas petrográficas.

A gagarinita tem fraturas preenchidas por criolita, assim como pode ocorrer com as bordas corroídas pela criolita, demonstrando uma formação precoce em relação aos bolsões criolíticos pegmatóides. Minerais da paragênese magmática do granito Madeira, como o pirocloro, quartzo e micas, ocorrem nas lâminas estudadas como relictos em meio aos bolsões de criolita. Não foram observadas relações diretas entre minerais magmáticos e a gagarinita. Assim, nas lâminas estudadas, a gagarinita pode representar um mineral da paragênese magmática ou pode ser um mineral de um estágio inicial da fase de formação dos bolsões criolíticos, hipótese esta mais provável em função sua ocorrência aparentemente restrita aos bolsões pegmatóides.
A gagarinita apresenta invariavelmente uma fase mineral associada como inclusões. Os padrões de textura resultantes da associação das duas fases são variáveis de um cristal para outro. A fase inclusa encontra-se, na grande maioria dos casos, distribuída com relativa uniformidade em toda a extensão dos grãos de gagarinita, inclusive na borda, tem dimensões semelhantes e segue, em alguns casos, uma ou mais orientações preferenciais (Fig. $2 \mathrm{~b}$ e c). Algumas vezes, pode ocorrer coalescência dos cristais inclusos, resultando em formas mais alongadas, assemelhando-se a strings e stringlets (Fig. 2d). Mais raramente, cristais da fase inclusa podem ter tamanhos distintos, com uma orientação preferencial menos evidente (Fig. 2a) e distribuição mais irregular, podendo ser, nestes casos, como ocorreu na primeira amostra de gagarinita encontrada (Bastos Neto et al., 2004) interpretada como uma fase mineral pré-existente incluída durante o crescimento da gagarinita. Para investigar essa possibilidade, procurou-se exaustivamente por mineral semelhante nas demais porções da rocha, seja na matriz ou dentro dos demais minerais, verificando-se que ele ocorre apenas na gagarinita. Coerentemente, constatou-se, também, que todos os cristais de gagarinita apresentam tais texturas, embora os padrões possam variar de um cristal para outro. A partir destas observações a hipótese de origem por exsolução passou a ser privilegiada em detrimento de origens por inclusão de uma fase precoce ou por co-precipitação das duas fases. No contato da gagarinita com a criolita (Fig. 2a), observa-se que a formação da fase exsolvida foi anterior à cristalização da criolita.

As investigações ao MEV mostraram que a passagem entre a gagarinita e a fase inclusa é abrupta e que em cada um desses minerais os elementos químicos distribuem-se de forma bastante homogênea.

Análises modais foram efetuadas numa população de grãos de gagarinita abrangendo os diversos padrões texturais de exsolução e ângulos de cortes dos cristais, a fim de obter uma proporção representativa da fase exsolvida em relação à fase hospedeira. A distribuição de valores obtida levou a considerar o valor médio ( $26 \%$ de fase exsolvida em relação a gagarinita hospedeira) como representativo.

A determinação precisa de todas as propriedades ópticas da fase exsolvida foi dificultada pelo tamanho diminuto dos grãos $(0,01 \mathrm{~mm}$ até $0,4 \mathrm{~mm}$, com média de $0,05 \mathrm{~mm})$. Ela é incolor e as cores de interferência são de primeira ordem, com birrefringência 0,005 -0,007; o mineral é U(-). Foram observadas inclusões fluidas e minerais opacos, estes últimos provavelmente representam inclusões previamente existentes na gagarinita.

Química Mineral Os resultados das análises por MSE da gagarinita e as respectivas fórmulas estruturais são apresentados na tabela 1 . $O$ cálculo de fórmula estrutural foi feito com base em $2(\mathrm{Ca}+\mathrm{Y}+\mathrm{ETR})$.

Os resultados das análises por MSE da fase exsolvida são apresentados na tabela 2 . Constatou-se que a composição deste mineral é muito distinta de exemplos de gagarinita da literatura, notadamente pela ausência quase total de $\mathrm{Na}$, Ca e Y. Os balanços de carga obtidos calculando-se a fórmula estrutural como para uma gagarinita forneceram valores da ordem de $-1,50$, considerados excessivos. Tendo em vista que o único fluoreto que tem composição química compatível com a obtida para a fase exsolvida é a fluocerita, a fórmula estrutural da fase exsolvida (Tab. 2) foi calculada considerando tratar-se deste mineral e o melhor resultado obtido foi o efetuado para o somatório de cátions igual a 1 .

A figura 3 apresenta uma comparação entre os conteúdos médios de ETR da gagarinita e da fase exsolvida, respectivamente. Os dois minerais apresentam comportamentos opostos. A gagarinita é caracterizada por empobrecimento em ETRL e 

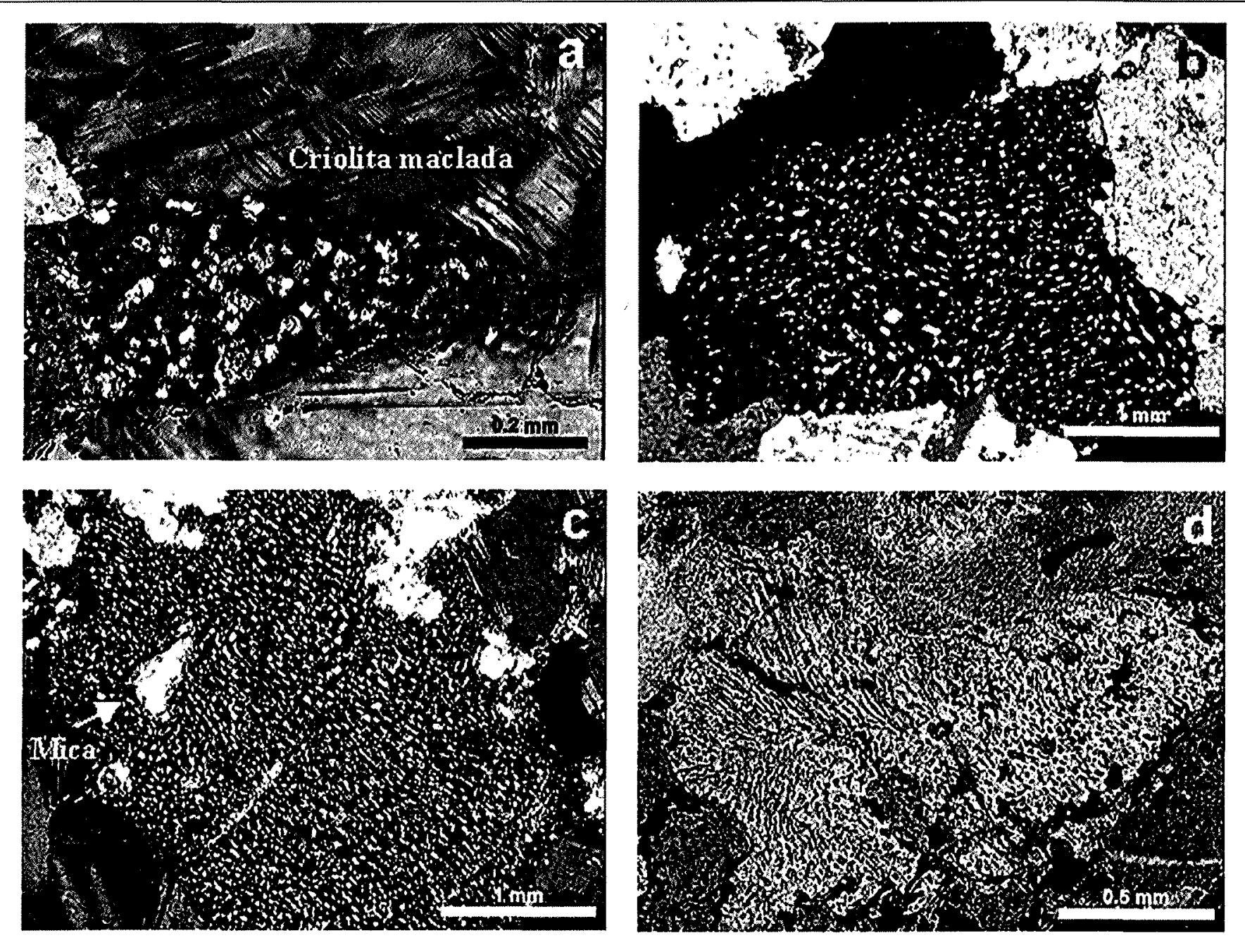

Figura 2: Fotomicrografias de diferentes padrões de exsolução na gagarinita de Pitinga: a- gagarinita com grãos da fase exsolvida de dimensões irregulares e sem orientação preferencial, é corroída por criolita maclada; $b$-textura de exsolução com orientação incipiente; $c$ - gagarinita com fase exsolvida com orientação pronunciada; $d$ - padrão de orientação na forma de stringlets.

enriquecimento em ETRP e anomalia negativa em Eu; a fase exsolvida é enriquecida em ETRL, empobrecida em ETRP e tem anomalia positiva em Eu.

Correlações entre os ETR foram testadas na gagarinita e na fase exsolvida. No primeiro mineral, a única correlação positiva significativa de elementos isolados ocorre entre o $\mathrm{Sm}$ e o $\mathrm{Nd}$ (coeficiente de correlação: $+0,80$ ). Foram constatadas correlações negativas com valores menos significativos $(>-0,74)$, que permitiram definir dois grupos de elementos: i) $\Sigma(\mathrm{La}, \mathrm{Ce}$, $\mathrm{Nd}, \mathrm{Sm}$ e Eu) e ii) $\Sigma(\mathrm{Gd}, \mathrm{Y}, \mathrm{Er}$ e $\mathrm{Yb})$. Isso indica que os ETRL + ETRM competem pelo mesmo sítio cristalográfico que os ETRP. O Dy é uma exceção, o que deve ser investigado em trabalhos futuros.

$\mathrm{Na}$ fase exsolvida, $\mathrm{Nd}, \mathrm{Sm}$ e Eu têm correlações positivas entre si $(+0,72$ a $+0,92)$. Verifica-se também que o $\Sigma E T R L$ (La + Ce) correlaciona negativamente com o LETRM $(-0,92)$. Porém, os ETRP têm um comportamento complexo, onde só Gd se correlaciona positivamente com o Sm $(+0,79)$.

Análises por DRX Os difratogramas obtidos (Fig. 4) apresentam unicamente os picos correspondentes à gagarinita. $\mathrm{O}$ cálculo dos parâmetros cristalográficos da gagarinita foi efetuado assumindo-se que a gagarinita do granito Madeira pertence ao grupo espacial $\mathrm{P}_{3} / \mathrm{m}$. Os parâmetros assim obtidos são compa- tíveis com os da literatura (Tab. 3).

Observa-se que os parâmetros cristalográficos calculados para a gagarinita do granito Madeira, provavelmente não correspondam exclusivamente a este mineral. As posições dos picos de DRX, bem como a largura e meia altura, que são variáveis consideradas pelo programa utilizado para este tipo de cálculo, podem ter sido levemente modificadas por influência da presença da fase exsolvida.

\section{DISCUSSÕES}

Texturas de exsolução As texturas aqui interpretadas como de exsolução são similares a alguns padrões comumente descritos na literatura, como o da exsolução de ilmenita na hematita (Augustithis 1995). Em silicatos, o caso clássico é o da formação das pertitas, pela exsolução de albita a partir do feldspato alcalino (Smith 1974). Entretanto, cabe avaliar sucintamente as possibilidades alternativas, pois o caso aqui apresentado é o primeiro descrito em fluoreto. A idéia de tratar-se de inclusão mineral, com a cristalização primeiro da "fase exsolvida" e posteriormente de gagarinita não explicaria a orientação dos grãos da "fase exsolvida" e nem o fato da gagarinita ser a única fase hospedeira. Também foi avaliada a possibilidade de tratar-se de processos de substituição ou de co-precipitação. No primeiro caso, a substituição da gagarinita por outro mineral ocorreria 
Tabela 1: Resultados das análises de gagarinita por microssonda eletrônica.

\begin{tabular}{|c|c|c|c|c|c|c|c|c|c|c|}
\hline & AG1 & AG2 & AG3 & AGAl & AGA2 & $\mathrm{AG} 20$ & $\mathrm{AG} 21$ & $\mathrm{AG} 24$ & AY5 & AY7 \\
\hline $\mathrm{F}$ & 36,76 & 37,92 & 36,17 & 38,44 & 38,83 & 37,41 & 40,27 & 37,47 & 34,86 & 38,51 \\
\hline $\mathrm{Na}$ & 2,09 & 2,25 & 1,91 & 1,80 & 1,80 & 3,51 & 1,55 & 1,69 & 1,46 & 2,04 \\
\hline $\mathrm{Al}$ & n.d. & n.d. & n.d. & n.d. & n.d. & n.d. & n.d. & n.d. & n.d. & n.d. \\
\hline $\mathrm{Si}$ & n.d. & n.d. & n.d. & n.d. & n.d. & n.d. & n.d. & n.d. & n.d. & n.d. \\
\hline $\mathrm{Ca}$ & 8,04 & 8,00 & 7,96 & 8,07 & 8,32 & 8,37 & 8,34 & 7,65 & 8,20 & 7,77 \\
\hline $\mathrm{La}$ & n.d. & n.d. & n.d. & n.d. & 0,01 & n.d. & 0,02 & 0,04 & 0,02 & n.d. \\
\hline $\mathrm{Ce}$ & 0,37 & 0,36 & 0,74 & 0,26 & 0,44 & 0,49 & 0,45 & 0,38 & 0,68 & 0,53 \\
\hline $\mathrm{Nd}$ & 2,51 & 1,84 & 2,44 & 1,51 & 1,89 & 1,91 & 1,87 & 1,95 & 2,63 & 2,16 \\
\hline $\mathrm{Sm}$ & 1,99 & 1,91 & 2,04 & 1,82 & 1,82 & 1,92 & 1,78 & 1,82 & 1,96 & 1,88 \\
\hline $\mathrm{Eu}$ & 0,06 & 0,04 & 0,06 & 0,08 & 0,04 & 0,04 & 0,03 & 0,14 & 0,06 & 0,13 \\
\hline Gd & 4,17 & 4,17 & 4,07 & 4,33 & 4,35 & 4,12 & 4,20 & 4,26 & 4,17 & 4,14 \\
\hline Dy & 7,24 & 7,11 & 7,12 & 7,32 & 7,18 & 7,13 & 6,79 & 6,74 & 7,03 & 6,78 \\
\hline Er & 3,74 & 3,82 & 3,82 & 3,86 & 3,74 & 3,63 & 3,75 & 3,81 & 3,67 & 3,63 \\
\hline $\mathrm{Yb}$ & 1,51 & 1,43 & 1,32 & 1,48 & 1,30 & 1,48 & 1,43 & 1,42 & 1,54 & 1,44 \\
\hline $\mathrm{Y}$ & 31,10 & 31,48 & 30,74 & 32,11 & 30,73 & 31,04 & 31,23 & 30,69 & 31,26 & 30,90 \\
\hline Total & 99,56 & 100,32 & 98,41 & 101,08 & 100,45 & 101,04 & 101,70 & 98,05 & 98,49 & 100,85 \\
\hline \multicolumn{11}{|c|}{ Fórmula Estrutural na base de $(\mathrm{Ca}+\mathrm{ETRT}+\mathrm{Y})=2$} \\
\hline $\mathrm{F}$ & 5,56 & 5,80 & 5,51 & 5,83 & 5,92 & 5,68 & 6,12 & 5,88 & 5,21 & 5,97 \\
\hline $\mathrm{Na}$ & 0,26 & 0,28 & 0,24 & 0,23 & 0,23 & 0,44 & 0,19 & 0,22 & 0,18 & 0,26 \\
\hline $\mathrm{Ca}$ & 0,58 & 0,58 & 0,58 & 0,58 & 0,60 & 0,60 & 0,60 & 0,57 & 0,58 & 0,57 \\
\hline $\mathrm{Ce}$ & 0,01 & 0,01 & 0,02 & 0,01 & 0,01 & 0,01 & 0,01 & 0,01 & 0,01 & 0,01 \\
\hline $\mathrm{Nd}$ & 0,05 & 0,04 & 0,05 & 0,03 & 0,04 & 0,04 & 0,04 & 0,04 & 0,05 & 0,05 \\
\hline $\mathrm{Sm}$ & 0,04 & 0,04 & 0,04 & 0,03 & 0,04 & 0,04 & 0,03 & 0,04 & 0,04 & 0,04 \\
\hline $\mathrm{Gd}$ & 0,08 & 0,08 & 0,08 & 0,08 & 0,08 & 0,08 & 0,08 & 0,08 & 0,08 & 0,08 \\
\hline Dy & 0,13 & 0,13 & 0,13 & 0,13 & 0,13 & 0,13 & 0,12 & 0,12 & 0,12 & 0,12 \\
\hline $\mathrm{Er}$ & 0,06 & 0,07 & 0,07 & 0,07 & 0,06 & 0,06 & 0,06 & 0,07 & 0,06 & 0,06 \\
\hline $\mathrm{Yb}$ & 0,03 & 0,02 & 0,02 & 0,02 & 0,02 & 0,02 & 0,02 & 0,02 & 0,03 & 0,02 \\
\hline$Y$ & 1,00 & 1,03 & 1,00 & 1,04 & 1,00 & 1,01 & 1,01 & 1,03 & 1,00 & 1,02 \\
\hline
\end{tabular}

principalmente na borda; no caso estudado, na maioria dos cristais, as formas do tipo strings e stringlets irradiam-se do centro para a borda da gagarinita. $O$ caráter subédrico dos cristais inclusos também desfavorece a hipótese de substituição. Quanto à hipótese de co-precipitação, em casos como o do quartzo e feldspato (textura gráfica) ou augita em ortopiroxênio (MacKenzie 1982), por exemplo, as duas fases minerais ocorrem intercrescidas, mas, na mesma amostra, também formam cristais individuais. No presente caso, as duas fases ocorrem sempre juntas. Por outro lado, não há evidências desta textura ter alguma relação causal com o aporte do fluido responsável pela formação da criolita, a qual é nitidamente posterior à formação da fase exsolvida e não interfere na sua distribuição dentro dos grãos de gagarinita, cujas bordas são corroídas pela criolita. Assim, o único processo que explicaria as texturas encontradas na gagarinita de Pitinga é o de exsolução e este processo ocorreu antes da formação da criolita dos bolsões pegmatóides.

Condições de formação As temperaturas de homogeneização mais altas obtidas na criolita dos bolsões são da ordem de $370^{\circ} \mathrm{C}$ (Bastos Neto et al. 2004). Esta deve representar, portanto, uma temperatura mínima para a formação da gagarinita hospedeira e da fase exsolvida. A gagarinita inicial teria se formado numa temperatura superior à destas duas últimas. No caso da gagarinita inicial ser um mineral geneticamente ligado aos bolsões (hipótese mais provável), sua formação e o subseqüente processo de exsolução devem ter ocorrido numa faixa de temperatura pouco acima dos $370^{\circ} \mathrm{C}$. No caso de uma origem magmática, as temperaturas seriam maiores, mas registra-se que as temperaturas de cristalização do albita granito foram inferiores a $500^{\circ} \mathrm{C}(\mathrm{Costi} 2000)$.

Segundo Costi (2000), os elevados teores de $\mathrm{Fe}_{2} \mathrm{O}_{3}$ dos feldspatos e mica tetraferríferas litiníferas indicam que o albita granito cristalizou sob condições de $f \mathrm{O}_{2}$ relativamente elevada. Segundo Minuzzi (2004), o processo de columbitização do pirocloro magmático pelo fluido formador dos bolsões também ocorreu em condições levemente oxidantes, mesmo na porção inferior do DCM. Portanto, a cristalização da gagarinita inicial, seja ela magmática ou hidrotermal, ocorreu provavelmente sob condições oxidantes, ou seja, na presença simultânea dos cátions $\mathrm{Eu}^{+2} \mathrm{e} \mathrm{Eu}^{+3}$. Por outro lado, considerando-se que eventuais modificações de parâmetros como $\mathrm{pH}$ e $f \mathrm{O}_{2}$ do meio externo não tiveram influência no interior dos cristais de gagarinita quando da exsolução, a razão $\mathrm{Eu}^{+2} / \mathrm{Eu}^{+3}$ do sistema representado pelas 3 fases minerais em conjunto não foi modificada.

Composição da gagarinita inicial e da gagarinita pós-exsolução A composição da gagarinita antes da exsolução foi estimada somando-se as composições das fases hospedeira e 
Tabela 2: Resultados das análises da fase exsolvida por microssonda eletrônica.

\begin{tabular}{|c|c|c|c|c|c|c|c|c|c|c|}
\hline & AY1 & AY2 & AY4 & AY6 & AY8 & $\mathrm{AF} 2$ & AF4 & AF20 & $\mathrm{AF} 22$ & AF28 \\
\hline $\mathrm{F}$ & 33,78 & 35,33 & 34,41 & 34,34 & 35,27 & 36,30 & 34,52 & 36,29 & 36,26 & 33,63 \\
\hline $\mathrm{Na}$ & n.d. & n.d. & n.d. & n.d. & 0,03 & n.d. & n.d. & 0,02 & n.d. & n.d. \\
\hline $\mathrm{Al}$ & 0,01 & 0,02 & n.d. & 0,01 & n.d. & n.d. & n.d. & n.d. & n.d. & 0,01 \\
\hline $\mathrm{Si}$ & n.d. & 0,01 & 0,03 & n.d. & 0,06 & 0,04 & n.d. & 0,01 & 0,01 & 0,05 \\
\hline $\mathrm{Ca}$ & 0,03 & 0,11 & 0,03 & 0,11 & 0,02 & 0,08 & 0,07 & 0,04 & 0,10 & 0,12 \\
\hline $\mathrm{La}$ & 12,92 & 10,42 & 11,38 & 14,68 & 9,24 & 8,96 & 12,24 & 10,89 & 10,38 & 8,35 \\
\hline $\mathrm{Ce}$ & 42,90 & 43,50 & 42,87 & 45,10 & 41,87 & 40,73 & 44,29 & 43,57 & 42,39 & 41,84 \\
\hline $\mathrm{Nd}$ & 7,86 & 10,36 & 10,52 & 6,61 & 13,25 & 13,19 & 7,98 & 9,48 & 10,57 & 13,13 \\
\hline $\mathrm{Sm}$ & 1,04 & 1,33 & 1,20 & 0,67 & 1,42 & 1,40 & 0,76 & 1,06 & 1,30 & 1,42 \\
\hline $\mathrm{Eu}$ & 0,38 & 0,62 & 0,51 & 0,43 & 0,60 & 0,76 & 0,51 & 0,48 & 0,56 & 0,72 \\
\hline $\mathrm{Gd}$ & 0,25 & 0,45 & 0,38 & 0,43 & 0,32 & 0,37 & 0,38 & 0,38 & 0,33 & 0,42 \\
\hline Dy & 0,20 & 0,31 & 0,11 & 0,28 & 0,14 & 0,18 & 0,31 & 0,23 & 0,17 & 0,30 \\
\hline $\mathrm{Er}$ & 0,04 & n.d. & n.d. & 0,02 & n.d. & n.d. & n.d. & n.d. & n.d. & n.d. \\
\hline $\mathrm{Yb}$ & 0,02 & 0,01 & 0,07 & n.d. & n.d. & 0,01 & n.d. & 0,02 & n.d. & 0,05 \\
\hline$Y$ & 0,27 & 0,33 & 0,19 & 0,49 & 0,15 & 0,22 & 0,30 & 0,27 & 0,29 & 0,24 \\
\hline Total & 99,84 & 103,12 & 101,80 & 103,42 & 102,50 & 102,44 & 101,67 & 102,98 & 102,54 & 100,56 \\
\hline \multicolumn{11}{|c|}{ Fórmula Estrutural na base de 1 cátion } \\
\hline $\mathrm{F}$ & 3,77 & 3,84 & 3,76 & 3,65 & 3,86 & 4,04 & 3,79 & 4,01 & 4,03 & 3,70 \\
\hline $\mathrm{Ca}$ & 0,00 & 0,01 & 0,00 & 0,01 & 0,00 & 0,00 & 0,00 & 0,00 & 0,01 & 0,01 \\
\hline $\mathrm{La}$ & 0,20 & 0,15 & 0,17 & 0,21 & 0,14 & 0,14 & 0,18 & 0,16 & 0,16 & 0,13 \\
\hline $\mathrm{Ce}$ & 0,65 & 0,64 & 0,64 & 0,65 & 0,62 & 0,62 & 0,66 & 0,65 & 0,64 & 0,62 \\
\hline $\mathrm{Nd}$ & 0,12 & 0,15 & 0,15 & 0,09 & 0,20 & 0,20 & 0,12 & 0,14 & 0,16 & 0,19 \\
\hline $\mathrm{Sm}$ & 0,01 & 0,02 & 0,02 & 0,01 & 0,02 & 0,02 & 0,01 & 0,01 & 0,02 & 0,02 \\
\hline $\mathrm{Eu}$ & 0,01 & 0,01 & 0,01 & 0,01 & 0,01 & 0,01 & 0,01 & 0,01 & 0,01 & 0,01 \\
\hline $\mathrm{Gd}$ & 0,00 & 0,01 & 0,01 & 0,01 & 0,00 & 0,00 & 0,01 & 0,01 & 0,00 & 0,01 \\
\hline $\mathrm{Y}$ & 0,01 & 0,01 & 0,00 & 0,01 & 0,00 & 0,01 & 0,01 & 0,01 & 0,01 & 0,01 \\
\hline
\end{tabular}

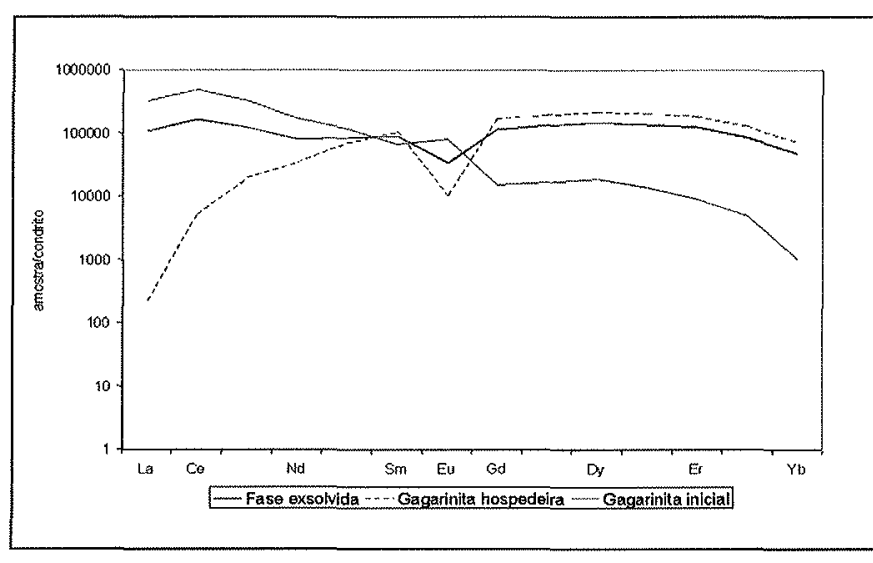

Figura 3: Padrão de ETR, comparando a gagarinita inicial calculada com a fase hospedeira e a fase exsolvida, normalizadas pelo condrito.

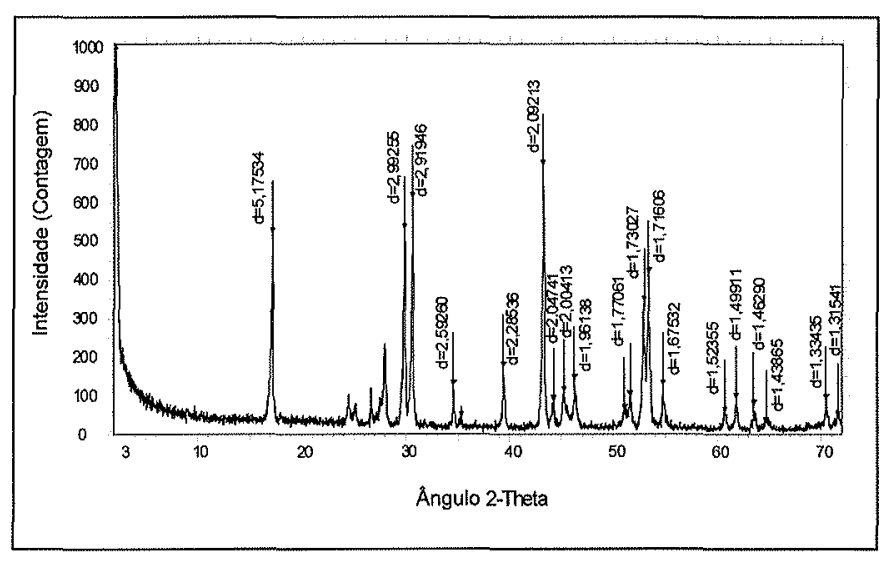

Figura 4: Difratograma de raios $X$ da gagarinita de Pitinga. 
Tabela 3: Fórmula mineral, grupo espacial e parâmetros cristalográficos de gagarinita com diferentes composições.

\begin{tabular}{|c|c|c|c|c|c|}
\hline & Fórmula mineral de gagarinita de & $\Sigma$ cátions & Grupo & \multicolumn{2}{|c|}{ Parâmetros cristalográficos ( ) } \\
\hline 1 & $\mathrm{Na}_{0,8} \mathrm{Ca}_{0,8} \mathrm{Y}_{1,2} \mathrm{~F}_{6}$ & 2,8 & P3 & $a=5,9900$ & $c=3,5300$ \\
\hline 2 & $\mathrm{Na}_{1,23} \mathrm{Ca}_{0,12} \mathrm{Y}_{1,28} \mathrm{ETR}_{0,24} \mathrm{~F}_{6}$ & 2,87 & $\mathrm{P}_{3} / \mathrm{m}$ & $a=5,9855$ & $c=3,5469$ \\
\hline 3 & $\mathrm{NaCa}(\mathrm{Y}, \mathrm{ETR}) \mathrm{F}_{6}$ & 3 & $\mathrm{P}_{6} / \mathrm{m}$ & $a=6,0403$ & $\mathrm{c}=3,5899$ \\
\hline 4 & $\mathrm{Na}_{0,6} \mathrm{Ca}_{0,95} \mathrm{ETR}_{0,32} \mathrm{Y}_{0,72} \mathrm{~F}_{5,41}$ & 2,9 & $\mathrm{P}_{6} / \mathrm{m}$ & $a=5,987(1)$ & $c=3,5413(7)$ \\
\hline 5 & $\mathrm{Na}_{0,23} \mathrm{Ca}_{0,53} \mathrm{Y}_{0,48} \mathrm{ETR}_{0,99} \mathrm{~F}_{7.69}$ & 2,19 & $\mathrm{P}_{3} / \mathrm{m}$ & & \\
\hline 6 & $\mathrm{Na}_{0,24} \mathrm{Ca}_{0,58} \mathrm{Y}_{1,01} \mathrm{ETR}_{0,39} \mathrm{~F}_{5,81}$ & 2,22 & $\mathrm{P}_{6} / \mathrm{m}$ & $\begin{array}{l}a=5,9933 \\
a=5,9885\end{array}$ & $\begin{array}{l}c=3,5417 \\
c=3,5248\end{array}$ \\
\hline
\end{tabular}

1-Voronkov et al. (1962) apud Mincryst; 2- Kabalov et al. (1993) apud Mincryst; 3Kamenetskaya e Kamenetskii (1994) apud Mincryst; 4- Hugues e Drexler (1994); 5gagarinita inicial; 6- gagarinita (fase hospedeira após a exsolução).

hóspede. Neste cálculo, as porcentagem em volume $(74 \%$ de gagarinita e $26 \%$ de fase exsolvida) obtidas pela análise modal foram corrigidas para porcentagem em peso (66\% de gagarinita e $34 \%$ de fase exsolvida), considerando as densidades dos dois minerais. A composição da gagarinita inicial difere bastante da gagarinita descrita por Voronkov et al. (1962, apud Mincryst) que não contém ETR e que é bem mais rica em Na e Ca do que a de Pitinga. Em relação às demais gagarinitas, ela apresenta uma importante característica comum a todas que é a presença significativa dos cátions $\mathrm{Na}, \mathrm{Ca}, \mathrm{ETR}$ e $\mathrm{Y}$, sendo este último elemento abundante em todas as gagarinitas descritas. Por seu conteúdo em Ca ser significativamente maior do que o de $\mathrm{Na}$ (razão $\mathrm{Na} / \mathrm{Ca}$ em torno de 0,5 ), ela assemelha-se à descrita por Hughes e Drexler (1994), mas distingue-se das demais, nas quais $\mathrm{Ca}$ e $\mathrm{Na}$ ocorrem em proporções iguais ou este último elemento é bem mais abundante. Por outro lado, ela destaca-se (a) por ser a mais rica em ETR; (b) por ter o maior somatório de (Y + ETR); (c) por ser a única com razão Y/ETR próxima a 1; e (d) pelo baixo conteúdo de $(\mathrm{Na}+\mathrm{Ca})$, que parece contrabalançar o enriquecimento em ETR.

Quanto à distribuição dos ETR, a gagarinita inicial destaca-se por conter simultaneamente conteúdos altos de ETRL e ETRP, contrastando bastante com a gagarinita de Hughes e Drexler (1994) que contém praticamente apenas ETRP. A gagarinita de Stepanov e Severov (1961, apud Hughes e Drexler, 1994) tem conteúdos significativos de $\mathrm{Nd}$ e Sm, na mesma ordem de grandeza da gagarinita inicial, mas possui concentrações de La e Ce (especialmente este último elemento) bem menores, de modo que seu conteúdo total de ETRL é bem inferior ao da gagarinita inicial.

A composição da gagarinita hospedeira difere da gagarinita inicial pelo baixo conteúdo de ETRL. Esta modificação a torna uma gagarinita de composição bastante similar às demais da literatura (exceto pela gagarinita sem ETR de Voronkov et al.
1962 apud Mincryst), notadamente pelo conteúdo de ETR e razão Y/ETR na mesma ordem de grandeza das demais.

Os ETR e o processo de exsolução Diante da inexistência de literatura sobre exsolução em fluoretos, as causas da exsolução aqui interpretada só podem ser aventadas a partir de uma comparação das 3 fases minerais (gagarinita inicial, gagarinita hospedeira e fase exsolvida), mais particularmente no que tange aos ETR. A gagarinita inicial apresenta um espectro de ETR (Fig. 3) bastante plano, com anomalia negativa de európio, semelhantemente ao espectro de ETR do AGN encaixante dos bolsões criolíticos (Costi 2000). Embora não se disponha de dados experimentais sobre o comportamento dos ETR na gagarinita, parece possível que, nas condições de formação da gagarinita inicial, este mineral seja um amplificador linear da composição de ETR do fluido a partir do qual se formou, como ocorre com a fluorita (Marchand et al. 1976).

A figura 3 ilustra muito bem a notável repartição dos ETR entre as três fases minerais. $\mathrm{O}$ espectro plano da gagarinita inicial contrasta com o fracionamento dos ETRL da gagarinita hospedeira. Nesta, ocorre um enriquecimento contínuo do La para o Sm, cujos raios iônicos decrescem neste mesmo sentido. Por outro lado, observa-se que este último elemento é o balizador do processo, estando presente em iguais proporções nas 3 fases em questão. Conseqüentemente, acredita-se que um possível abaixamento da temperatura após a formação da gagarinita inicial tenha ocasionado a desestabilização da estrutura cristalina que exsolveu seletivamente os cátions do sítio ${ }^{\mathrm{IX}}$ maiores do que o Sm. Este processo resultou na formação de uma fase exsolvida enriquecida em ETRL (do La ao $\mathrm{Nd}$ ) e, conseqüentemente, de uma fase hospedeira empobrecida nestes mesmos elementos. Neste processo quantidades mínimas de ETRP foram mobilizados para a fase exsolvida. Observa-se na figura 3 que o Eu não seguiu o comportamento dos demais ETR de raios iônicos 
menores do que o Sm, delineando-se uma possível anomalia po-sitiva na fase exsolvida e uma acentuação da anomalia negativa de Eu na gagarinita hospedeira em relação à gagarinita inicial. Este comportamento do Eu distinto dos demais ETR pode estar relacionado à presença simultânea dos cátions $\mathrm{Eu}^{+2} \mathrm{e} \mathrm{Eu}^{+3}$.

A fase exsolvida, um novo mineral? O único fluoreto que tem composição química semelhante à da fase exsolvida é a fluocerita. Assim, o cálculo de sua fórmula estrutural foi efetuado na base do somatório de cátions igual a 1 (Tab. 1). A variação da fórmula estrutural assim calculada é:

$$
\mathrm{Ce}_{0,53-0,66} \mathrm{La}_{0,09-0,26} \mathrm{Nd}_{0,08-0,26} \mathrm{Sm}_{0,01-0,04} \mathrm{Eu}_{0,01} \mathrm{Y}_{0-0,03} \mathrm{~F}_{3,3-4,14}
$$

Comparativamente a fluoceritas da literatura, a composição da fase exsolvida é similar à descrita por (Clark 1993 apud Minerology Database), cuja fórmula é $\mathrm{Ce}_{0,9} \mathrm{La}_{0,1} \mathrm{~F}_{3}$. As demais fórmulas definidas para fluocerita distinguem-se bastante. Algumas fórmulas contêm muito mais $\mathrm{La}$ do que $\mathrm{Ce}$, como $\mathrm{LaF}_{3}$ (Maximov \& Schulz 1985; Zalkin \& Templeton 1985 apud Mincryst) ou $\mathrm{La}_{0,9} \mathrm{Ce}_{0,1} \mathrm{~F}_{3}$ (Clark 1993 apud Minerology Database). Outras contêm conteúdos significativos de $\mathrm{Gd}$ ou $\mathrm{Sr}$, como $\mathrm{Gd}_{0,8} \mathrm{Ca}_{0,2} \mathrm{~F}_{2,8}$ (Ostrochenko et al. 1985 apud Mincryst) e $\mathrm{La}_{0,85} \mathrm{Sr}_{0,15} \stackrel{0.8}{\mathrm{~F}}{ }_{2,85}$ (Radaev et al. 1991 apud Mincryst) ou, ainda, não contém La, como $\mathrm{CeF}_{3}$ (Wyckoff 1964 apud Mincryst). Na comparação com as fluoceritas de diferentes procedências descritas por Styles e Young (1983), verifica-se que os conteúdos de ETR da fase exsolvida situam-se dentro dos intervalos mínimo e máximo já quantificados, porém sua composição não é idêntica a nenhuma fluocerita. Por outro lado, as composições de fluocerita são todas diferentes entre si.

Do ponto de vista da estrutura do mineral, observa-se que, embora as constantes paramétricas calculadas para gagarinita do granito Madeira sejam semelhantes às obtidas por Voronkov et al. (1962 apud Mincryst) e Kabalov et al. (1993 apud Mincryst) e Hugues e Drexler (1994), há que se considerar que esses parâmetros provavelmente não correspondam exclusivamente a este mineral devido à presença da fase exsolvida. Nos difratogramas não se nota nenhum pico de fluocerita, o que deveria ocorrer se a fase exsolvida fosse este mineral. Conseqüentemente, não se pode aqui definir que a fase exsolvida seja fluocerita. Finalmente, a possibilidade dela ter uma estrutura semelhante à da gagarinita é problemática por serem compostos com razões cátions/ F distintas (1/2 para a gagarinita e $1 / 3$ para a fase exsolvida). Como as propriedades ópticas que puderam ser definidas não são diagnósticas, considera-se aqui que a questão permanece em aberto e somente poderá ser definida pelos estudos que serão subseqüentemente realizados.

CONSIDERAÇÕES FINAIS A gagarinita inicial de Pitinga formou-se anteriormente à criolita dos bolsões do DCM. Não foi possível, entretanto, precisar em que estágio exato da evolução do albita granito ela se formou. Ela pode ser um mineral magmático ou representar um mineral precoce do estágio de formação dos bolsões. Considerando que sua característica principal é o alto conteúdo de ETRL, a gagarinita da literatura à qual ela mais se assemelha também ocorre em granitos albitizados, associada em veios de quartzo-microlina. Em Pitinga, esta paragênese é mais típica da auréola pegmatóide do DCM.

Antes da exsolução, o sistema mineral formava uma solução sólida na qual as principais substituições eram regidas pela equação: $\square+2 \mathrm{ETR}^{3+} \Leftrightarrow \mathrm{Na}^{+}+\mathrm{Ca}^{2+}+\mathrm{Y}^{3+}$ Formou-se, assim, uma gagarinita inicial excepcionalmente rica em ETRL, cátions relativamente grandes, cuja presença foi compensada por vacâncias, notadamente no seu sítio de coordenação VI. Embora não se disponha de dados experimentais sobre a formação da gagarinita, o estudo realizado sobre a distribuição dos ETR parece indicar que, nas condições de formação da gagarinita inicial, este mineral possa ter se comportando como um amplificador quase linear da composição de ETR do fluido a partir do qual ele se formou, como ocorre com a fluorita.

A diminuição da temperatura foi a provável responsável pela desestabilização da estrutura mineral que exsolveu os cátions de ETR com raio iônico maior do que o do Sm, elemento que foi o balizador do processo de exsolução. A gagarinita hospedeira preservou praticamente todos os conteúdos de Y, ETRP (com exceção do $\mathrm{Sm}$ que repartiu-se entre ela e a fase exsolvida) e $\mathrm{Na}$ (e Ca), constituindo uma estrutura estável, menos afetada por vacâncias e com um balanço de cargas bastante equilibrado. A fase exsolvida é um fluoreto com razão cátions/fiúor $=1 / 3$, essencialmente constituído por $\mathrm{Ce}$ e $\mathrm{La}$, correspondendo a uma composição de fluocerita. Sua estrutura não pôde ser determinada: picos da fluocerita não foram identificados e uma estrutura semelhante à da gagarinita (razão cátions/flúor $=1 / 2$ ) parece pouco provável. Estudos subseqüentes serão necessários para definir sua natureza e relação com a fluocerita.

Agradecimentos Aos revisores da RBG pelas sugestões ao manuscrito. Aos geólogos J.M. Ferron e M. Prado da Mineração Taboca Ltda pelo apoio nos trabalhos de campo. Aos geólogos Dr. O. J. Marini, Dr. B.W. Ramos e Dr H. Jost (ADIMB) e Dr. E. T. Queiroz (DNPM) pelo apoio fornecido através de projeto FINEP-CTMINERAL. Ao CNPq pelas bolsas de produtividade de A.C. Bastos Neto e N.F. Botelho.

\section{Referências}

Almeida, M. E., Fraga, L. M. B., Macambira, M. J. B. 1997. New geochronological data of calc-alcaline granitoids of Roraima State, Brazil [abs.]. In: South American Symposium on Isotope Geology. Campos do Jordão, 34-35.

Åmli, R. \& Griffin, W. L. 1975. Microprobe analysis of REE minerals using empirical correction factors. American Mineralogist, 60 : 599-606.

Araújo Neto, H. \& Moreira, H. L. 1977. Projeto Estanho do Abonari. Manaus, DNPM/CPRM Relatório Final, vol 2.

Araujo, J. F. V., Montalvão, R. M. G., Lima, M. I. C., Fernandes, P. E. C. A., Cunha, F. M. B., Fernandes, C. A. C., Basei, M. A. S. 1976. Projeto RADAMBRASIL - Geologia da Folha SA.21, San- tarém, Brasil. Rio de Janeiro. DNPM, Levantamento de Recursos Naturais, 10, 17-130.

Augustithis, S-S. P. (Ed.) 1995. Atlas of the textural patterns of ore minerals and metallogenic processes. Walter de Gruyter and Co, New York, 659p.

Bastos Neto, A. C., Pereira, V. P., Minuzzi, O. R. R., Ferron, J. M., Prado, M., Ronchi, L. H., Lima, E. F., Frantz, J. C., Hoff, R., Rolim, S. B. A., Umann, L., Rocha, F. N., Flores, J. A. A., Oliveira, D., Pierozan, R. 2004. O depósito criolítico de Pitinga (Amazonas): Resultados preliminares. In: I Simpósio Brasileiro de Exploração Mineral. Ouro Preto, poster (CD-ROM)

Burnham, C.W. 1993. Least-squares refinement of crystallographic lat- 
tice parameters. Harvard University, Cambridge, MA 02138.

Costi, H. T. 2000. Petrologia de granitos alcalinos com alto fúor mineralizados em metais raros: o exemplo do Albita-granito da Mina Pitinga, Amazonas, Brasil. Tese de Doutorado, Instituto de Geociências, Universidade Federal do Pará, 345p.

Costi, H. T., Dall'Agnol, R., Moura, C. A. V. 2000. Geology and Pb$\mathrm{Pb}$ geochronology of paleoproterozoic volcanic and granitc rocks of the Pitinga Province, Amazonian Craton, Northem Brazil. Int. Geol. Rev., 42: 832-849.

Dall'Agnol, R., Costi, H. T., Borges, R. M. K. 2003. Estudos e projetos direcionados a depósitos minerais e distritos mineiros: "Caracterização de depósitos minerais em distritos mineiros da Amazônia", subprojeto: Pitinga-Estanho. Belém, UFPA, Relatório de compilação e integração de dados/Nota Explicativa ao Mapa Geológico $1: 25.000,11-23$

Faria, M. S. G., Luzardo, R., Pinheiro, S. S., Reis, N. J., Oliveira, M. J, R., Riker, S. R. L. 2000. Projeto Caracarai. Programa de levantamentos geológicos básicos do Brasil. CPRM Caracaraí, Folhas NA.20-Z-B e NA.20-Z-D inteiras e parte das follhas NA.20-Z-A, NA.20-Z-C, NA.21-Y-C e NA.21-Y-A. Estado de Roraima. Escala 1:500.000. Brasília, CPRM. Relatório Final (em CD-ROM).

Horbe, M. A., Horbe, A. C., Teixeira, J. T., Costi, H. T. 1985. Granito Madeira: Petrologia, petroquímica e mineralizações. In: $\mathrm{SBG}$, Simp. Geol. Amazônia, 2: 284-320.

Hughes, J. M. \& Drexler, J. W. 1994. Refinement of the structure of gargarinite- $(\mathrm{Y}), \mathrm{Na}_{\mathrm{x}}\left(\mathrm{Ca}_{\mathrm{x}} \mathrm{REE}_{2-\mathrm{x}} \mathrm{F}_{6}\right)$. The Canadian Mineralogist, 32 (3): $563-565$

Issler, R. S., Andrade, A. R. F., Montalvão, R. M. G., Guimarães, G., Silva, G. G. \& Lima, M. I. C. 1974. Geologia da Folha SA.22 - Belém. Brasil, Departamento Nacional de Produção Mineral. Projeto RADAMBRASIL. Folha SA.22 - Belém. Rio de Janeiro. Levantamento de Recursos Naturais 5: 7-182.

MacKenzie, W. S., Donaldson, C. H., Guilford, C. (Eds). 1982. Atlas of igneous rocks and their textures. Longman Scientific \& technical. New York, $148 \mathrm{p}$

Mandarino, J. A. \& Black, M. E. (Eds). 2004. Fleischer's glossary of mineral species. Mineralogical Record Inc., Tucson, $309 \mathrm{pp}$.

Marchand, L., Joseph, D., Touray, J. C., Treuil, M. 1976. Critères d'analyse géochimique des gisements de fluorine basée sur l'etude de la distribution des lanthanides, application aux gites de Maine. Mineral Deposita, 11: 357-379.

Méary, A., Touray, J. C., Galland, D., Jebrak, M. 1985. Interprétation de lánomalie en europium des fluorines hydrotermales. Données de la RPE. Aplication au gite de fluorine de Montroc (Tarn) - Chem. Geol, 48: 115-124.

Mincryst. Disponível em $<\mathrm{http}: / /$ database.iem.ac.ru/mincryst/index. php> Acesso em 5 jan. 2005.
Mineralogy Database. Disponivel em <http://www. webmineral.com/ data/Gagarinite-(Y).shtml >. Acesso em 5 jan. 2005.

Minuzzi, O. R. R. 2004. A columbitização do pirocloro da subfácies albita-granito de núcleo do Granito Madeira, Pitinga-AM: Relações com a gênese da mineralização criolítica. Monografia de exame de qualificação ao doutorado. Instituto de Geociências, Universidade Federal do Rio Grande do Sul, 156p.

Minuzzi, O. R. R. 2005. Gênese e evolução da mineralização de criolita, pirocloro e columbita da subfácies albita granito de núcleo, mina Pitinga, Amazonas, Brasil. Tese de doutorado, Instituto de Geociências, Universidade Federal do Rio Grande do Sul, 182p.

Minuzzi, O. R. R., Bastos Neto, A. C.; Pereira, V. P., Oliveira, D. 2005 [No prelo]. A Columbitização do Pirocloro da Subfácies AlbitaGranito de Núcleo do Granito Madeira, Pitinga-AM: Relações com a Gênese da Mineralização Criolítica. Rev. Bras. Geoc.

Programa Scion Image Beta 4.2. Disponível em $<\mathrm{http} / / \mathrm{www}$. scioncorp.com>. Acesso em: $28 \mathrm{dez} .2004$.

Santos, J. O. S.; Hartmann, L. A.; McNaughton, N. J. \& Fletcher, I. R. 2002. Timmin of mafic magmatism in the Tapajós Province (Brazil) and implications for the evolution of the Amazon Craton: evidence from baddeleyite and zircon U-Pb SHRIMP geochronology. Journal of South America Earth Science, 15: 409-429.

Schobbenhaus, C., Hoppe, A., Lork, A., Baumann, A. 1994. Idade de Magmatismo Uatumã no Norte do Cráton Amazônico, Escudo das Guianas (Brasil) - Primeiros Resultados. In: SBG, Congr. Bras. de Geol. 38, Camboriú, 2, Anais, p. 395-397.

Smith, J. V. 1974. Intimate feldspar intergrowth. In: Smith, J. V. \& Smith, B. F. (eds). Feldspar Minerals. Chemical and textural properties, 2, Springer-Verlag New York, pp.: 399-544.

Styles, M. T. \& Young, B. R. 1983. Fluocerite and its alteration products from the Afu Hills, Nigeria. Mineralogical Magazine, 47: 41-46.

Sverjenski, D. A. 1984. Europium redox equilibria in aqueous solution. Earth and Planet. Sci Lett. 67: 70-78

Teixeira, J. T., Costi, H. T., Minuzzi, O. R. R., Soares, E. A. A. 1992. Depósitos primários de criolita, cassiterita, xenotímio e columbita em apogranito - Mina de Pitinga (AM). In: SBG, Congr. Bras. de Geol. 37, São Paulo, 1, Anais, p. 212-213.

Teixeira, L. M. 2002. Caracterização de minerais portadores de terras raras e sua aplicação à petrologia e geocronologia de granitos das subprovincias Tocantins e Paranã, Goiás. Tese de doutorado, Instituto de Geociências, Universidade de Brasília. 354p.

Teixeira, W., Tassinari, C. C. G., Cordani, U. G. Kawashita, K. 1989. A review of the geochronology of the Amazonian Cráton: Tectonic implications. Precambrian Research, 42: 213-227.

Manuscrito A-1581 Revisão aceita em 14 de junho de 2006 